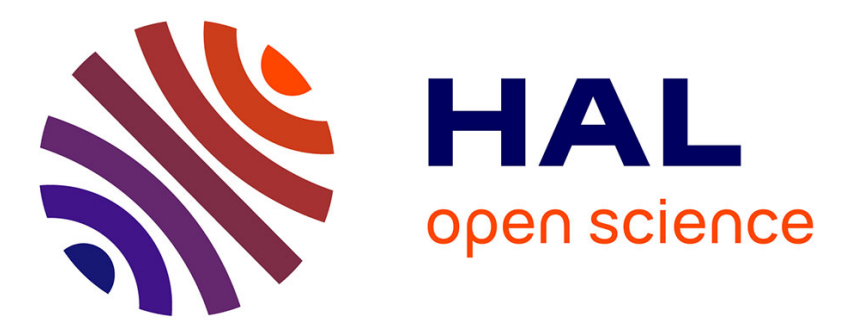

\title{
A new perfusion method adapted to rainbow trout (Salmo gairdneri) brain pituitary preparation for simultaneous electrophysiological recording and hormone secretion determination
}

\author{
T. Bailhache, G. Salbert, J.C. Guillet, C. Saligaut, Bernard Breton, P. Jego
}

\section{To cite this version:}

T. Bailhache, G. Salbert, J.C. Guillet, C. Saligaut, Bernard Breton, et al.. A new perfusion method adapted to rainbow trout (Salmo gairdneri) brain pituitary preparation for simultaneous electrophysiological recording and hormone secretion determination. Comparative Biochemistry and Physiology - A: Comparative Physiology, 1989, 94A (2), pp.305-313. 10.1016/0300-9629(89)90552-5 . hal-02728199

\section{HAL Id: hal-02728199 \\ https://hal.inrae.fr/hal-02728199}

Submitted on 2 Jun 2020

HAL is a multi-disciplinary open access archive for the deposit and dissemination of scientific research documents, whether they are published or not. The documents may come from teaching and research institutions in France or abroad, or from public or private research centers.
L'archive ouverte pluridisciplinaire HAL, est destinée au dépôt et à la diffusion de documents scientifiques de niveau recherche, publiés ou non, émanant des établissements d'enseignement et de recherche français ou étrangers, des laboratoires publics ou privés. 


\title{
A NEW PERFUSION METHOD ADAPTED TO RAINBOW TROUT (SALMO GAIRDNERI) BRAIN PITUITARY PREPARATION FOR SIMULTANEOUS ELECTROPHYSIOLOGICAL RECORDING AND HORMONE SECRETION DETERMINATION
}

\author{
T. Bailhache, ${ }^{*}$ G. Salbert, ${ }^{*}$ J. C. Guillet, $\dagger$ C. Saligaut, ${ }^{*}$ B. Breton $\ddagger$ and P. Jego* \\ *Laboratoire de Physiologie des Régulations, U.A. CNRS 256, Université de Rennes I, \\ †Laboratoire de Physiologie Animale, U.E.R. S.V.E., Université de Rennes I; and †Laboratoire de \\ Physiologie des Poissons, INRA, Campus de Beaulieu, 35042 Rennes Cédex, France
}

(Received 31 March 1989)

\begin{abstract}
The development of an in vitro brain-pituitary perfusion technique allowed both the measurement of gonadotropin release and the recording of electrical activity in various brain areas of the rainbow trout.

2. GnRH sensitive neurons were found in the nucleus preopticus (NPO).

3. Gonadotropin release was evoked after microinjections of LHRH-A into the pituitary or into the NPO.

4. Norepinephrine has been demonstrated to have a stimulatory effect on gonadotropin release.
\end{abstract}

\section{INTRODUCTION}

The teleost hypothalamo-pituitary system is unique among vertebrates, as there is a direct innervation of the pars distalis by the neurosecretory neurons of the hypothalamus (Peter and Fryer, 1983; Ball, 1981). The regulation of the pituitary secretions has been extensively studied, but many aspects remain unclear (Peter and Fryer, 1983). Several reasons can be evoked in order to explain the heterogeneity of conclusions in previous studies.

There are important differences in the regulation of the pituitary secretions between species: for example, in goldfish, the dopaminergic inhibition on gonadotropin $(\mathrm{GtH})$ release is intense and injection of pimozide (dopamine antagonist) is able to increase $\mathrm{GtH}$ release and to trigger ovulation; such an effect of pimozide is not found in other species like salmonids (review of Peter et al., 1986).

In vivo, pharmacological studies have been extensively developed to outline the mechanisms of regulation of pituitary hormonal secretions (Peter and Fryer, 1983). The main problem of the classical drug administration is due to the failure of knowing the precise distribution at the brain level. Some in vivo electrophysiological studies have been reported in the literature (Le Mevel and Mabin, 1985; Hayward, 1974). The main limitation of these in vivo approaches is due to the ambiguous determination of specific and reproductive stereotaxic coordinates, as a consequence of a constant development of brain during the growth of the fish.

In vitro studies have been developed in several fish species. Many studies using pituitary fragments,

Address all correspondence to T. Bailhache. dispersed cells or cultured cells, contributed to the determination of both receptors and biogenic substances involved in the regulation of pituitary hormone secretions (Chang et al., 1984; De Leeuw et al., 1986; Weil et al., 1986). These experimental procedures however did not respect the integrity of the hypothalamo-pituitary connection.

The development of an experimental procedure using a brain-pituitary preparation with an intact pituitary stalk appears then to be a good alternative to study the regulatory pathways of pituitary secretions and of gonadotropin secretion in particular.

Gonadotropin $(\mathrm{GtH})$ release has been previously reported to depend upon hypothalamic regulations which are mediated by a stimulatory effect of gonadotropin-releasing hormone (GnRH) and by an inhibitory effect of dopamine (review of Peter et al., 1986). Among hypothalamic areas involved in such a regulation, many authors have pointed out the preoptic area and especially the nucleus preopticus (NPO) (Peter and Fryer, 1983; Kah, 1986). GnRH cellular bodies were found in the NPO of the goldfish (Carassius auratus) (Kah et al., 1986), the African catfish (Clarius gariepinus) (Goos et al., 1985), the platy fish (Xyphophorus maculatus) (Schreibman et $a l ., 1983$ ) and the brown trout (Salmo trutta) (Breton et al., 1986). And dopamine cell bodies were also observed in the NPO of the goldfish, using an immunohistochemical method (Kah et al., 1984).

The aim of our work was to elaborate a functional brain-pituitary preparation perfused with an appropriate physiological buffer. To test the physiological significance of our preparation, we studied the multiunit activity (MUA) under basal conditions or with a depolarizing agent. We also aimed to determine the role of the NPO in the regulation of GtH release, 
focusing on microinjections of some pharmacological agents in either the NPO or the pituitary, with simultaneous electrophysiological recordings and $\mathrm{GtH}$ release measurements.

\section{MATERIALS AND METHODS}

Animals

Experiments were performed in female trout (Salmo gairdneri) (weight $1.5-2.5 \mathrm{~kg}$ ) in mid-vitellogenesis (oocyte diametcr $2 \mathrm{~mm}$ ) or in the periovulatory pcriod. Animals were supplied by Cornec fishfarm (France) and introduced in laboratory facilities (Laboratoire de Physiologie des Poissons INRA) 2 months before the beginning of the study. They were kept in $4 \mathrm{~m}^{3}$ aquaria in fresh water at $13 \pm 1{ }^{\circ} \mathrm{C}$, under a natural photoperiod cycle. Water was constantly flowing in a recirculating water system and aerated by an appropriate device.

\section{Dissecting and perfusion procedure}

The trout were killed by decapitation and the brain removed. Particular care is required in this step, since the integrity of the hypothalamo-pituitary system (pituitary stalk) had to be maintained for the experimental procedure.

Brains were quickly placed in a Petri dish filled with an appropriate HEPES buffer saline $\left(+4^{\circ} \mathrm{C}\right)$ (HBS, see below) and dissected according to the following procedure. A sagittal cut was made on both brain and pituitary. The right half brain section was discarded, and the remaining left sagittal preparation was dissected again. The final hemipreparation involved the olfactory bulb, the telencephalon. the preoptic area, the hypothalamus and the pituitary, taking care to maintain intact innervations between the diverse areas.

The final preparation (third ventricular side up) was then placed in a thermostatically controlled chamber $\left(+14^{\circ} \mathrm{C}\right)$ perfused with a HEPES buffer saline (HBS) $(\mathrm{NaCl} 133 \mathrm{mM}$, $\mathrm{KCl} 3 \mathrm{mM}, \mathrm{MgSO}_{4} 0.3 \mathrm{mM}, \mathrm{MgCl}_{2} 1 \mathrm{mM}, \mathrm{CaCl}_{2} 5 \mathrm{mM}$, HEPES $20 \mathrm{mM}$, glucose $10 \mathrm{mM}$, bovine serum albumin $0.1 \%$ ) saturated with oxygen. The flow rate of the perfusion was $12 \mathrm{ml} / \mathrm{hr}$. This chamber was adapted from the classical model of the Scottish chamber (Alger et al., 1984) and had a volume of $0.5 \mathrm{ml}$ (Fig. 1). The effluent medium was collected ( 1 sample every 2 or $5 \mathrm{~min}$ ) and kept at $-20^{\circ} \mathrm{C}$ for later $\mathrm{GtH}$ assays.

\section{Electrical recordings}

During all the perfusion procedure, two sets of concentric stainless steel bipolar electrodes (DISA, $40 \mathrm{~mm}$ length, $0.45 \mathrm{~mm}$ external diameter and $0.07 \mathrm{~mm}$ diameter platinum centertip) were placed perpendicular to the nucleus preopticus (NPO), the nucleus lateral tuberis (NLT) or the pituitary. NPO and NLT were located according to the rainbow trout brain atlas of Billard and Pcter (1982). The electrodes were connected to miniature differential preamplifiers with a low background noise $(<10 \mu \mathrm{V})$. The multi-unit activity (MUA) was filtered $(B P=100 \mathrm{~Hz}$. $1 \mathrm{kHz}$ ), amplified and monitored on an oscilloscope (Tektronix). A window discriminator allowed the MUA to be integrated as a frequency curve (Ratemeter analysis).

\section{Pharmacological studies}

They were performed between 180 and 400 min following the beginning of the perfusion. sGnRII (salmon GnRII) was applied to the entire preparation via the perfusion buffer during $15 \mathrm{~min}$ at a concentration of $10^{-7} \mathrm{M}$. Luteinizing hormone-releasing hormone-analogue (LHRH-A) and norepinephrine (NE) were locally injected through glass micropipettes (tip diameter $20 \mu \mathrm{m}$ ) at the NPO or the pituitary level.

Micropipettes, connected to a Hamilton syringe, allowed small volumes $(2 \mu 1)$ of pharmacological solutions to be delivered into brain structures (Alger et al., 1984). The tip of the pipette was driven under a stereomicroscope-micromanipulator device into the NPO $(20 \mu \mathrm{m}$ depth) or the pituitary $(0.5 \mathrm{~mm}$ depth). Injected quantities of LHRH-A and NE were $2 \times 10^{-11}$ and $2 \times 10^{-10} \mathrm{~mol}$, respectively. LHRH-A [des-gly ${ }^{10}\left(\mathrm{D}-\mathrm{Ala}{ }^{6}\right)$-LHRH] and NE (Norepinephrine hydrochloride) were purchased from Sigma (USA) and sGnRH was synthetized at the University of Bordeaux, by Drs G. Precigoux and S. Geoffre using the solid phase method of Meriffield (Breton et al., 1984).

\section{GtH assay}

$\mathrm{GtH}$ contents were determined in samples using a heterologous ELISA procedure: $20 \mu \mathrm{l}$ of each sample were

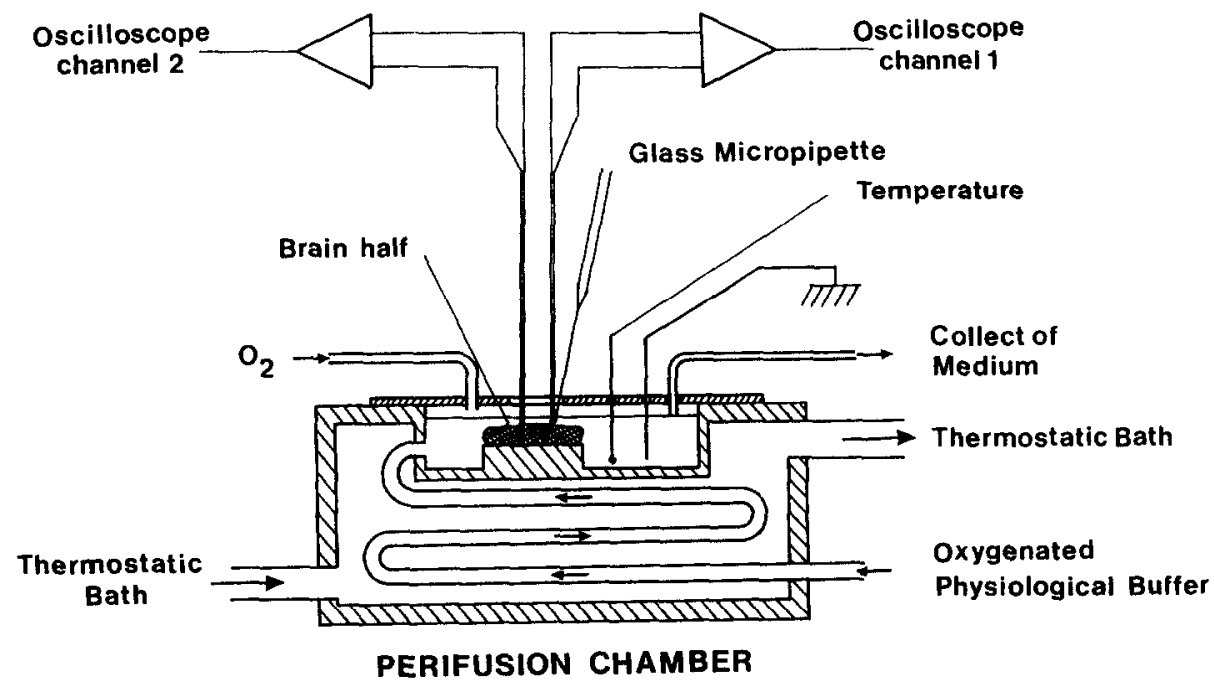

Fig. 1. Schematic drawing of the Plcxiglass perfusion chamber. The brain-half is placed in a temperaturecontrolled chamber $\left(14^{\circ} \mathrm{C}\right)$ supplied with previously oxygenated HEPES buffer saline. Furthermore, oxygen flows just above the medium level which is kept at $1 \mathrm{~mm}$ above the brain-pituitary preparation. The collecting tube is adjusted in order to get this constant level throughout the experiment. With an open "chimney" system, the preparation is freely accessible for the setting of recording electrodes and injection micropipettes, and their monitoring under the microscope. 
incubated until equilibrium with primary antibody $(1 / 200,000)$ directed against the $\beta$ subunit of $s G t H$, in microplate wells previously coated with standard $\mathrm{sGtH}$ $(2 \mathrm{ng} / \mathrm{ml})$ (final volume $200 \mu \mathrm{l})$. Antigen-antibody complexes were revealed by the PAP technique, using orthophenylenediamine (Sigma) as the chromogene. Optical densities of the wells were read on a microplate reader (DYNATECH) and GtH levels were determined with reference to a standard curve after Logit/Log transformation.

Statistical analysis used a non-parametric test of Mann and Whitney in order to compare $\mathrm{GtH}$ release evoked by drugs (drug-induced $\mathrm{GtII}$ release minus basal release).

\section{RESULTS}

\section{Basal electrical activity}

Our experimental procedure allowed MUA from different areas of the brain and the pituitary to be recorded. A spontaneous electrical activity (spikes of $50-100 \mu \mathrm{V}$ amplitude) was detectable at both the
NPO and the NLT levels. It appeared as bursts in the NPO but as a continuous firing in the NLT (Fig. 2A).

Bursts in the NPO were about $400 \mathrm{msec}$ in duration with silent intervals of $1 \mathrm{sec}$. The same sequence was reported directly in Fig. $2 \mathrm{B.1}$ and via the integrative system (ratemeter analysis) in Fig. 2B.2. At a slower speed (Fig. 2C), each burst appeared as a vertical brief deflexion. Moreover, the bursts amplitude (i.e. firing rate in the burst) was modulated in a rhythmic manner. This figure shows the typical bursting activity of the NPO: waves of bursts.

When the MUA was enhanced by a depolarizing agent $(\mathrm{KCl} 9 \mathrm{mM})$, its characteristics remained constant (i.e. waves of bursts in NPO and continuous firing in NLT) (Fig. 3).

\section{Effect of GnRH on MUA}

sGnRH, when added to the perfusion medium at a concentration of $10^{-7} \mathrm{M}$, induced MUA in both the
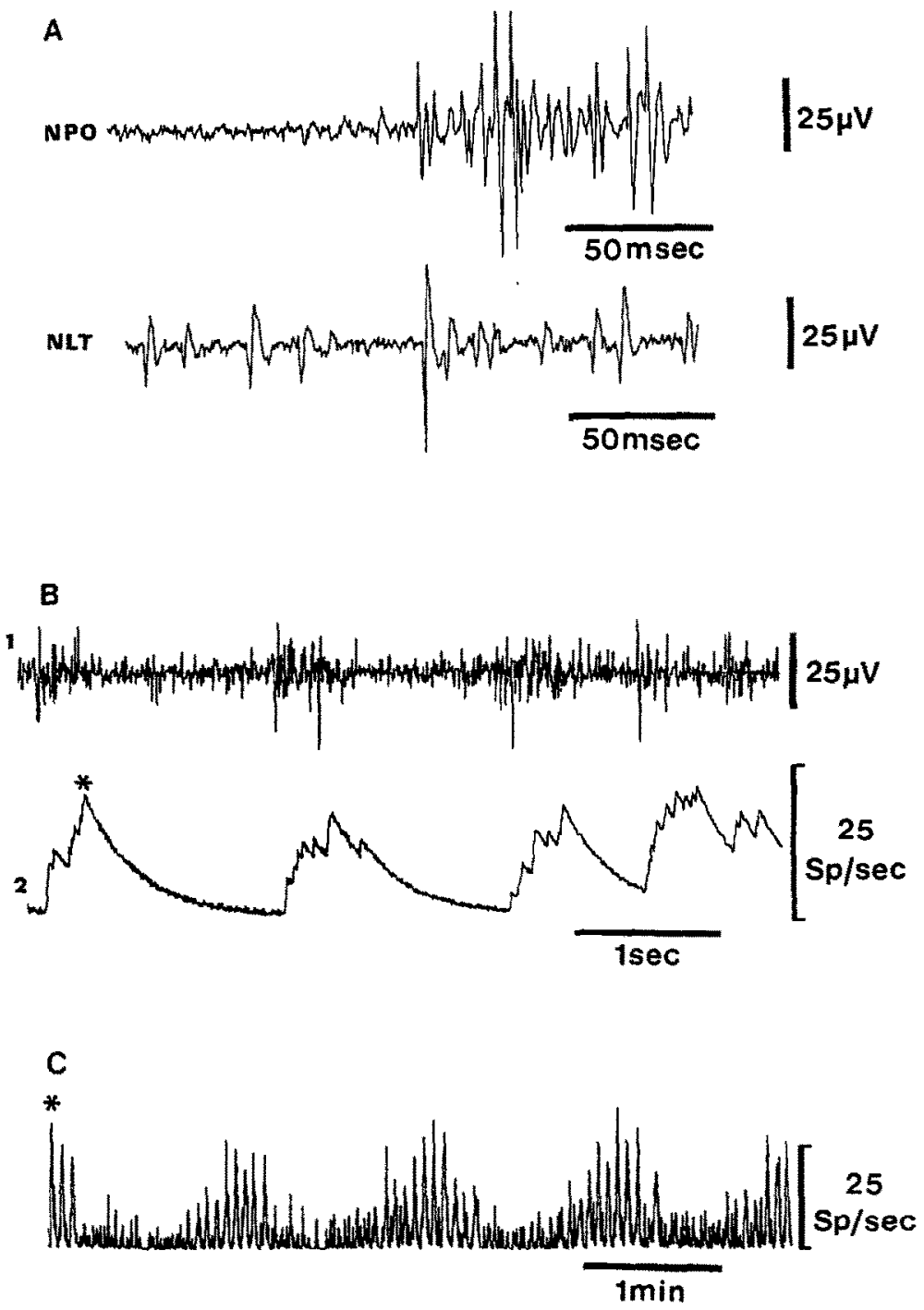

Fig. 2. Spontaneous multi-unit activity (MUA) recorded in the NPO and in the NLT. (A) Direct recordings of characteristic MUAs in the NPO (upper) and in the NLT (lower). (B) Direct recording (1) and ratemeter analysis (2) of the same MUA sequence in the NPO over a short period. (C) Ratemeter analysis of a characteristic MUA sequence in the NPO over a long period, showing the bursting pattern of this electrical activity (waves of bursts). "Similar bursts of MUA in (B) and (C). 


\section{$\mathrm{KCl} 9 \mathrm{mM}$}

\section{NLT

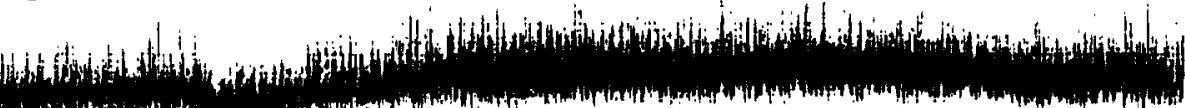

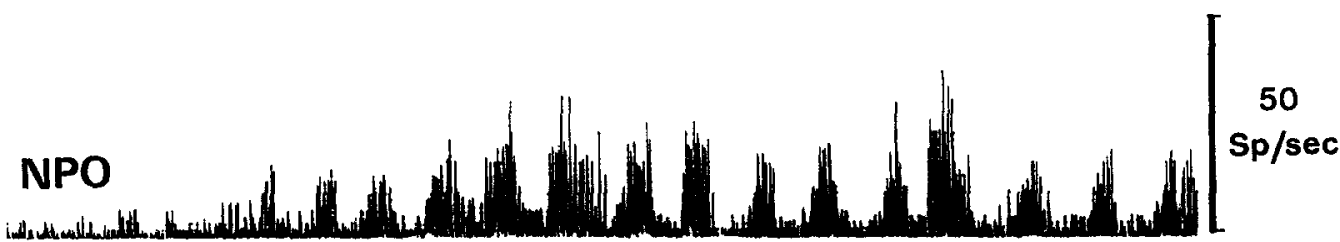

$5 \mathrm{~min}$

Fig. 3. Ratemeter analysis of MUA recorded simultaneously in the NPO and in the NLT before and during perfusion with a depolarizing agent $(\mathrm{KCl} 9 \mathrm{mM})$.

NPO and the pituitary. MUA at the NPO level appeared as bursts of spikes with a firing rate over 50 spikes/sec, and simultaneously synchronous bursts of spikes with a firing rate up to 10 spikes/sec have been recorded in the pituitary (proximal pars distalis location) (Fig. 4A). For both structures, bursts of spikes have been recorded at least $30 \mathrm{~min}$ after the sGnRH supply was stopped.

sGnRH also triggered MUA at the NLT level, with a continuous firing rate up to 15 spikes/sec: this activity however returned to basal levels immediately after the sGnRH removal (Fig. 4B).

A local injection of LHRH-A in the NPO (injected quantity $2 \times 10^{-11} \mathrm{~mol}$ ) also triggered a bursting MUA in the NPO with a firing rate up to 30 spikes/sec. This activity has been recorded during $40 \mathrm{~min}$ following the LHRH-A injection. Within the same time, no MUA was detectable at the NLT level (Fig. 4C).

\section{$G n R H$-induced $G t H$ release}

The responsiveness of pituitaries from mid-vitellogenesis female trouts to $\mathrm{sGnRH}$ was studied in vitro on either a brain-pituitary preparation or pituitary fragments alone.

When added to the perfusion medium of a brain pituitary preparation at a concentration of $10^{-7} \mathrm{M}$ (Fig. 5A), sGnRH induced a 2 -fold increase in $\mathrm{GtH}$ release, up to a plateau which lasted over $60 \mathrm{~min}$ following the sGnRH removal. sGnRH also induced MUA in the NPO which reached its maximum firing rate at the end of the SGnRH perfusion. Bursts of MUA were recorded in the NPO during $60 \mathrm{~min}$ following the sGinRH removal.

sGnRH, applied in the same way on perfused pituitary fragments, caused a transient increase in GtH release (1.5 fold) (Fig. 5B). This evoked release
A
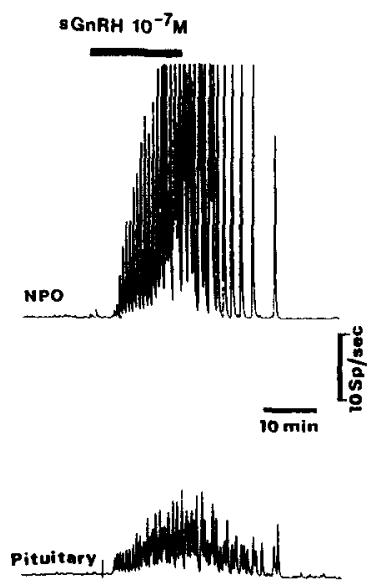

B

$\operatorname{sGnRH} 10^{-7} \mathrm{M}$
C

Fig. 4. Ratemeter analysis of MUA recorded simultaneously in the NPO and in the pituitary (A) or simultaneously in the NPO and in the NLT $(B, C)$ : effect of perfusion with sGnRH $10^{-7} \mathrm{M}(\mathrm{A}, \mathrm{B})$ or local injection of $2 \times 10^{-11} \mathrm{~mol}$ LHRH-A in the NPO (C). In (A), before sGnRH administration, the electrode was placed at the level of the proximal pars distalis in the pituitary, in such a place that evoked potentials could be recorded after electrical stimulation of the NPO. 

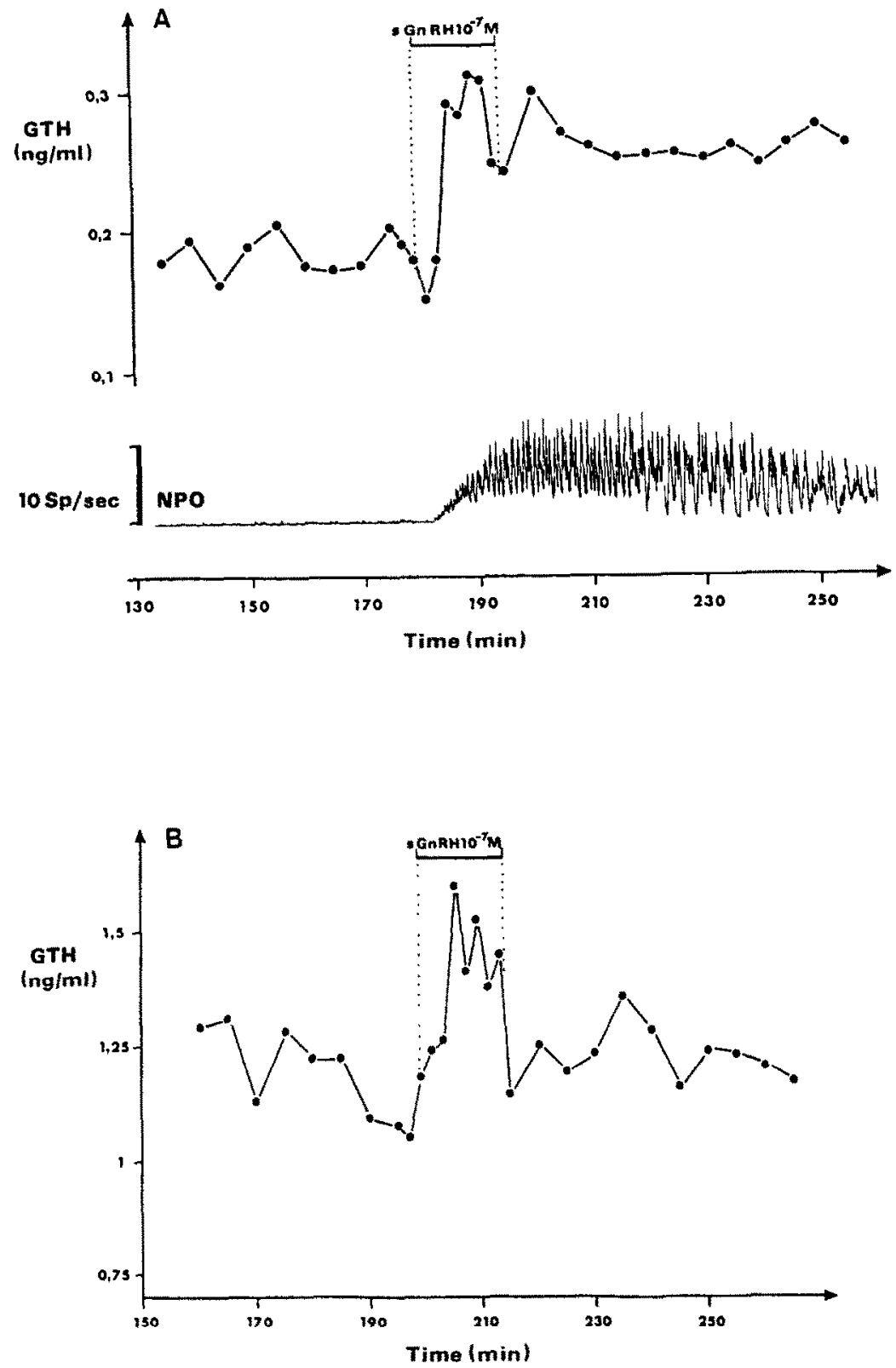

Fig. 5. Changes in GtH release and MUA in the NPO before and after perfusion with sGnRH $10^{-7} \mathrm{M}$ : (A) using a brain-pituitary preparation from a vitellogenesis female trout. Note the sGnRH-evoked MUA recorded in the NPO which shows a bursting pattern (ratemeter analysis); (B) using pituitary fragments from a vitellogenesis female trout.

was time-related with the presence of sGnRH in the perfusion medium and returned to basal level after sGnRH removal.

\section{Pharmacological studies by microinjections}

Microinjections of pharmacological solutions were made in either the NPO or the pituitary of brainpituitary preparations of female trouts in the periovulatory period.

Control injections in the NPO did not modify the $\mathrm{GtH}$ release (Fig. 6A), but a significant increase was observed after direct injections in the pituitary. Basal values were restored $10 \mathrm{~min}$ following the solvent injections.
NE did not modify the GtH release when administered in the NPO (Fig. 6B). However, when injected directly in the pituitary, a great increase was observed (up to $900 \%$ ) when compared to HBS-evoked GtH release, but values returned to basal level within $35 \mathrm{~min}$.

LHRH-A, when injected in the NPO, significantly increased $\mathrm{GtH}$ release $(150 \%)$ when compared to control injection. A similar increase was also observed when injected in the pituitary (up to $200 \%$ ), when compared to HBS-evoked GtH release (Fig. $6 \mathrm{C}$ ). Futhermore a sustained high release of $\mathrm{GtH}$ was obseved during more than $1 \mathrm{hr}$ after these LHRH-A injections. 


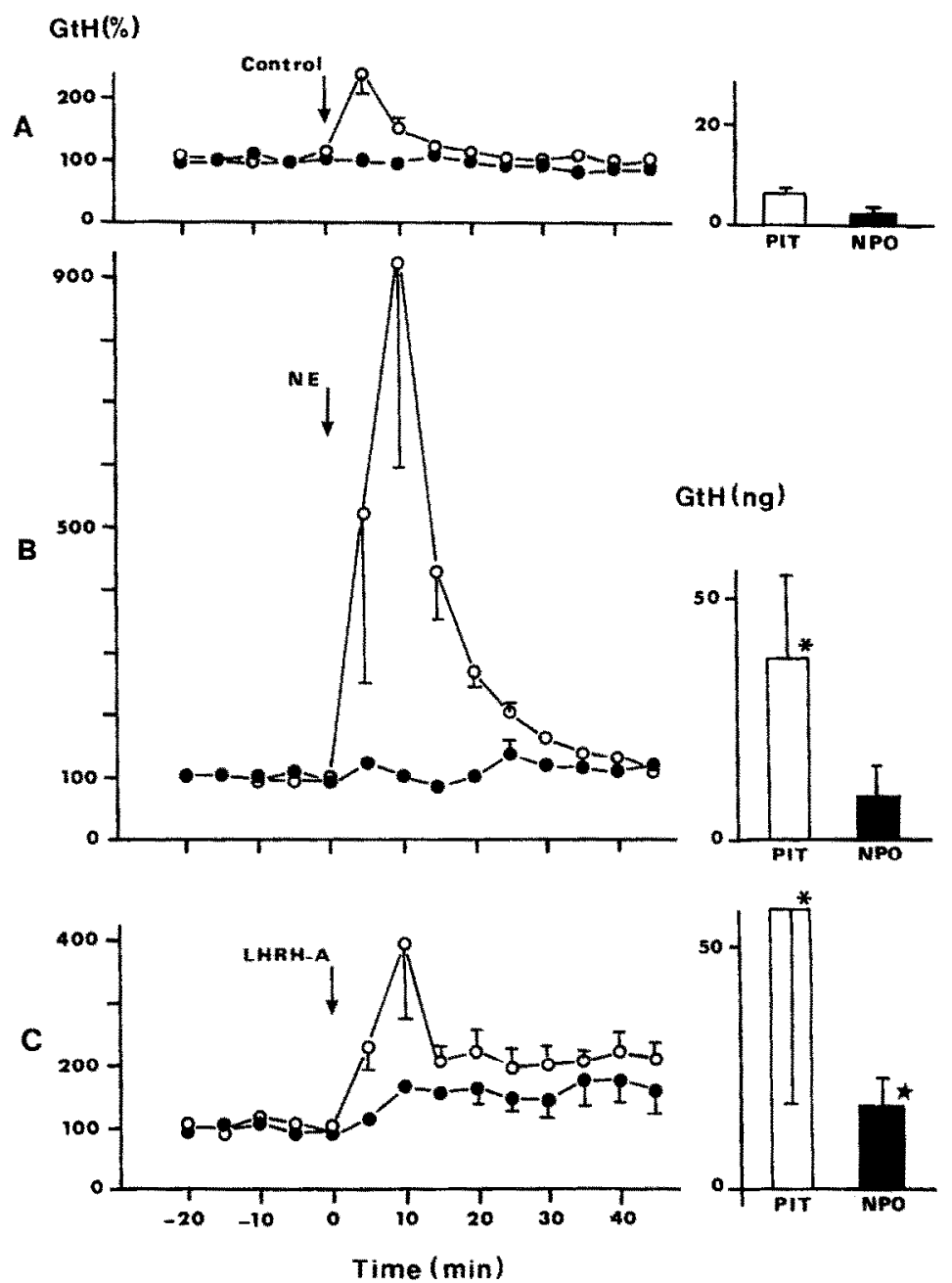

Fig. 6. Changes in GtH release before and after microinjections of $2 \mu 1$ of different solutions: (A) $2 \mu 1$ HEPES buffer saline (B) norepinephrine $\left(2 \times 10^{-10} \mathrm{~mol}\right)$, and (C) LHRH-A $\left(2 \times 10^{-11} \mathrm{~mol}\right)$, either in the pituitary $(O)$ or in the NPO (O). Data are expressed (left) as percent of the mean basal level (value $100=4.5 \pm 0.75 \mathrm{ng}$ ) or (right) as net evoked GtH release during the $45 \mathrm{~min}$ following the injection (mean \pm SEM). * Significantly different $(P<0.05 ; n=4)$ from control injection in the pituitary. Significantly different $(P<0.05 ; n=3)$ from control injection in the NPO.

\section{DISCUSSION}

We have previously demonstrated, using the same experimental procedure, that MUA could be recorded in the NPO and in the NLT over $10 \mathrm{hr}$, and that $2 \mathrm{mM}$ monosodium glutamate (a neuroexcitatory agent), when applied via the perfusion medium, induced electrical activity at various times during the perfusion, from 100 to $600 \mathrm{~min}$ (Bailhache et al., 1986). Similar results were obtained in this study, after perfusion with a high $\mathrm{K}^{+}$medium $(9 \mathrm{mM}$ potassium chloride), which increased the characteristic MUA in the NPO and in the NLT (bursts in the NPO and continuous firing in the NLT).

The firing rate pattern of MUA recorded in the NPO was in good agreement with in vivo electrophysiological recordings (Le Mevel and Mabin, 1985).

In a previous report, $\mathrm{KCl}(50 \mathrm{mM})$ evoked gonadotropin release from the pituitary at various times throughout the duration of experiments, from 100 to $600 \mathrm{~min}$ (Bailhache et al., 1988).

MUA stability has been previously demonstrated to be closely related to the survival of diverse physiological preparations: a lack in oxygen supply (i.e. anoxia) is thus known to provoke a transient increase of MUA, followed by cell death (Fujiwara et al., 1987). The constant oxygenation of both the perfusion medium and the chamber prevented such a cell damaging in our study. No changes in basic MUA were observed throughout the present experiments (between 100 and $400 \mathrm{~min}$ ) (data not shown).

These previous experiments demonstrated that the functional integrity of our preparation was kept for a period of $600 \mathrm{~min}$ at least.

Pharmacological substances have been chosen for their known activity in similar studies.

The concentration of sGnRH, when applied to the preparation via the perfusion medium was chosen as the lowest $\left(10^{-7} \mathrm{M}\right)$ able to increase both MUA 
and gonadotropin release. This concentration was moreover similar to those previously reported in the literature for endocrinological studies on diverse fish species (MacKenzie et al., 1984; Weil et al., 1986).

LHRH-A was previously demonstrated to be a potent agonist of GnRH in various fish species, using either in vivo or in vitro experiments (Peter, 1983; De Leuw et al., 1986; Chang et al., 1984; MacKenzie et al., 1984).

NE was demonstrated to have a stimulatory effect on GtH release in the goldfish (Carassius auratus) (Chang et al., 1984).

sGnRH, when added to the perfusion medium, induced synchronous bursts of MUA in both the pituitary and the NPO. These bursts of MUA were still detectable $30 \mathrm{~min}$ after the removal of GnRH in the perfusion medium. Similar bursts of MUA have also been recorded in the NPO after LHRH-A injections in the NPO. These recordings give evidence for the presence of GnRH-sensitive neurons in the NPO and suggest that sGnRH is able to activate a hypothalamo-pituitary pathway.

sGnRH, when added to the perfusion medium, increased $\mathrm{GtH}$ release from pituitary fragments, and this increase was closely related to the presence of the sGnRH in the perfusion medium. But a different GtH release pattern was observed for the brainpituitary preparation, suggesting two different effects of $\mathrm{GnRH}$ in this last experiment. First, a direct effect on gonadotrophs as shown by the increase of GtH release during GnRH perfusion, and second, an effect on GnRH-sensitive neurons in the hypothalamus which are involved in the sustained high $\mathrm{GtH}$ release.

An increase of MUA at the NPO level appeared moreover to be time-related with high levels of $\mathrm{GtH}$ release but further experiments must be performed in order to delineate whether cause-effect relationships between MUA in the NPO and the sustained high level of GtH release could be supported.

We notice that basal levels of $\mathrm{GtH}$ release were not the same in these two experiments. This can be explained by an individual variability (our experiments were carried out on separate fishes). But, we can also suggest that the low spontaneous GtH release found in the brain-pituitary perfusion procedure, could be partially mediated by a spontaneous tonic inhibitory effect of the hypothalamus on the pituitary.

Further interesting information was given by the microinjections of pharmacological agents in either the NPO or the pituitary. The solvent, when injected in the NPO, did not modify the GtH release. But such an injection in the pituitary ( $2 \mu 1$ of HBS) induced a transient $\mathrm{GtH}$ release, probably as a consequence of an increase in pressure in the pituitary.

LHRH-A, when injected into the pituitary, induced $\mathrm{GtH}$ release: these data agree with previous in vivo and in vitro studies (review of Peter et al., 1986). Moreover, such a sustained evoked release has been previously reported by Van Der Kraak et al. (1983), using in vivo i.p. injections of LHRH-A in the Coho salmon. These authors suggested that the prolonged effect of LHRH-A was linked to the great stability of this molecule.
LHRH-A, when injected in the NPO, also increased $\mathrm{GtH}$ release. The main problem in this experiment concerns a possible leakage of the drug during the injection in the NPO, with a diffusion in the perfusion medium, followed by a direct stimulation of the gonadotrophs in the pituitary. Such a hypothesis might be neglected in our experimental procedure because NE, a potent GtH-releasing agent when injected in the pituitary, was unable to induce any increase in $\mathrm{GtH}$ release when locally injected into the NPO. The absence of MUA at the NLT level during LHRH-A injections in the NPO is another control showing that there is no important leakage of LHRH-A during the injection. These results show the presence, in the NPO, of GnRH-sensitive neurons involved in the stimulation of $\mathrm{GtH}$ release.

The effect of NE at the pituitary level is interesting: such an increase in $\mathrm{GtH}$ release (about $900 \%$ ) has not already been reported in the rainbow trout. A stimulatory effect of $\mathrm{NE}$ on $\mathrm{GtH}$ release was however supported by Chang et al. (1984), using both pituitary fragments and pituitary dispersed cells from the goldfish (Carassius auratus).

sGnRH, in the perfusion medium, and LHRH-A, locally injected in the NPO, induced an increase of MUA in the NPO and in the pituitary, and an increase in pituitary $\mathrm{GtH}$ release. These data demonstrate for the first time the existence of GnRHsensitive neurons in the brain, and more especially in the NPO of the rainbow trout. These data also comfort the presence of an intact pituitary stalk in our experiments. Further experiments are, however, required in order to characterize these preoptic GnRH-sensitive neurons.

Such a sensitivity of hypothalamic neurons to $\mathrm{GnRH}$ has been reported in the rat (Herbison et al., 1984), where arcuate neurons in vitro were found to show excitation-inhibition sequences in response to a continuous LHRH perfusion. In fishes, the GnRH action at the pituitary level is now well known (review of Kah, 1986; Peter et al., 1986) but up to date there was no data concerning its action at the brain level. Our study gives evidence for a neurotransmitter or a neuromodulator role of the GnRH at the brain level in the rainbow trout. The presence of two molecular forms of $\mathrm{GnRH}$ in the brain of the rainbow trout (Sherwood et al., 1986), and moreover the differential distribution of these two molecular forms of GnRH in the goldfish (Yu et al., 1988), suggest a different role for each molecular form.

The preoptic area seems to be an important centre involved in the regulation of reproduction. It was demonstrated to be an area which concentrates sex steroid hormones in various fish species (Davis et al., 1977; Demski and Hornby, 1981) and shows an important aromatase activity which has been found to vary throughout the reproductive cycle in the goldfish (Pasmanik and Callard, 1988). The steroid hormones are known for their role in the regulation of the GtH release in fishes (Billard and Peter, 1977). And arginine vasopressine, which has been found to be present in preoptic magnocellular neurons projecting in the pituitary of various species (Goossens et al., 1977), has been reported to increase $\mathrm{GtH}$ release in the Sailfin molly (Poecilia latipinna) (Groves and Batten, 1986). 
Because of its neural connections with both the olfactory system and the pituitary (Hayward, 1974), and the presence of both $\mathrm{GnRH}$ and dopamine in preoptic neurons (see review in $\mathrm{Kah}, 1986$ ), NPO could play an integrative role in the regulation of reproduction by external and internal factors (Demski and Hornby, 1981). The GnRH sensitivity of preoptic neurons shown in this study is of major interest for the understanding of such a regulation.

In conclusion, our data demonstrate that the development of a brain-pituitary perfusion method is a good alternative for endocrinological studies and could be a useful procedure to delineate the role of hypothalamic neurons in the regulation of pituitary hormone secretions in fishes. Our experimental procedure allows both the measurement of hormone secretions and simultaneous recordings of MUA in various brain structures, in association with local microinjections of pharmacological agents.

The integrity of the preparation, specially the hypothalamo-pituitary pathways, was demonstrated using both electrophysiological and biochemical methods. The presence of GnRH-sensitive neurons in the NPO and a stimulatory effect of NE on GtH release were also demonstrated for the first time in the rainbow trout. Further experiments are however required to characterize the nature of neurons presenting such a sensitivity.

The study of temporal relationships between MUA and hormone secretions are of major interest for the understanding of hypothalamic regulations of $\mathrm{GtH}$ secretion in fishes, because of the pulsatile pattern of its release, as demonstrated by Zohar et al. (1986) in the rainbow trout.

Acknowledgements-We thank Dr A. Bourdeau for proofreading the manuscript. This work was supported by grant of the GCS-BBA: Groupement de Cooperation Scientifique, Bases Biologiques pour l'Aquaculture.

\section{REFERENCES}

Alger B. E., Dhanjal S. S., Dingledine R., Garthwaite J., Henderson G., King G. L., Lipton P., North A., Schwartzkroin P. A., Sears T. A., Segal M., Whittingham T. S. and Williams J. (1984) Appendix: Brain slice methods. In Brain Slices (Edited by Dingledine R.), pp. 421-437. Plenum Press, New York.

Bailhache T., Guillet J. C., Breton B. and Jego P. (1986) Etude électrophysiologique in vitro de l'hypothalamus de la truite arc-en-ciel. Ann. Endocr, 47, 14N.

Bailhache T., Guillet J. C. Boujard D., Breton B. and Jego P. (1988) Relations fonctionnelles hypothalamo-hypophysaires dans le contrôle de la sécrétion gonadotrope chez la truite: étude in vitro. Ann. Endocr. 49, 12N.

Ball J. N. (1981) Hypothalamic control of the pars distalis in fishes, amphibians and reptiles. Gen. comp. Endocr. 44, 135-170.

Billard R. and Peter R. E. (1977) Gonadotropin release after implantation of anti-estrogens in the pituitary and hypothalamus of goldfish, Carassius auratus. Gen. comp. Endocr. 32, 213-220.

Billard R. and Peter R. E. (1982) A stereotaxic atlas and technique for nuclei of the diencephaion of rainbow trout (Salmo gairdneri). Reprod, Nutr. Develop. 22, 1-25.

Breton B., Motin A., Kah O., Lemenn F., Geoffre S., Precignoux G. and Chambolle P. (1984) Dosage radioimmunologique homologue d'un facteur hypothalamique de stimulation de la fonction gonadotrope hypophysaire de saumon sGnRH, C.R. Acad. Sci., Paris, 299, série III, 9, 383-388.

Breton B., Motin A., Billard R., Kah O., Geoffre S. and Precigoux G. (1986) Immunoreactive gonadotropinreleasing hormone-like material in brain and the pituitary gland during the periovulatory period in the brown trout (Salmo trutta L.): relationships with the plasma and pituitary gonadotropin. Gen. comp. Endocr. 61, 109-119. Chang J. P., MacKenzie D. S., Gould D. R. and Peter R. E. (1984) Effects of dopamine and norepinephrine on the in vitro spontaneous and gonadotropin-releasing hormone-induced gonadotropin release by dispersed cells or fragments of the goldfish pituitary, Life Sci. 35, $2027-2033$

Davis R. E., Morrell J. I. and Pfaff D. W. (1977) Autoradiographic localization of sex steroid-concentrating cells in the brain of the teleost Macropodus opercularis (Osteichthyes: Belontiidae). Gen. comp. Endocr, 33, 496-506.

De Leeuw R., Goos H. J. Th. and Van Oordt P. J. W. J. (1986) The dopaminergic inhibition of the gonadotropinreleasing hormone-induced gonadotropin release: an in vitro study with fragments and cell suspensions from pituitaries of the African Catfish, Clarias gariepinus (Burchell). Gen. comp. Endocr. 63, 171-177.

Demski L. S. and Hornby P. J. (1981) Hormonal control of fish reproductive behavior: brain-gonadal steroid interactions. Can. J. Fish. Aquat. Sci. 39, 36-47.

Fujiwara N., Higashi H., Shimoji $\mathrm{K}$. and Yoshimura M. (1987) Effects of hypoxia on rat hyppocampal neurones in vitro. $J$. Physiol., Lond. 384, 131-151.

Goos H. J. Th., De Leeuw R., De Zoeten-Kamp C., Peute J. and Bisher S. (1985) Gonadotropin-releasing hormoneimmunoreactive neuronal structures in the brain and pituitary of the African catfish, Clarias gariepinus (Burchell). Cell Tiss. Res. 241, 539-596.

Goossens N., Dierickx K. and Vandesande F. (1977) Immunocytochemical localization of vasotocin and isotocin in the preopticohypophysial neurosecretory system of teleosts. Gen. comp. Endocr. 32, 371-375.

Groves D, J. and Batten T, F, C. (1986) Direct control of the gonadotroph in a teleost, Poecilia latipinna. II. Neurohormones and neurotransmitters. Gen. comp. Endocr. 62, 315-326.

Hayward J. N. (1974) Physiological and morphological identification of hypothalamic magnocellular neuroendocrine cells in goldfish preoptic nucleus. I. Physiol. Lond. 239, 103-124.

Herbison A. E., Hubbard J. I. and Sirett N. E. (1984) LH-RH in picomole concentrations evokes excitation and inhibition of rat arcuate neurones in vitro. Neurosci. Lett. 46, 311-315

Kah O. (1986) Central regulation of reproduction in teleosts. Fish. Physiul. Biuchem. 2, 25-34.

Kah O., Chambolle P., Thibault J. and Geffard M. (1984) Existence of dopaminergic neurons in the preoptic region of the goldfish. Neuroscience 48, 293-298.

Kah O., Breton B., Dulka J. G. Nunez-Rodrriguez J., Peter R. E., Corrigan A., Rivier J. E. and Vale W. W. (1986) A reinvestigation of the GnRH (gonadotrophin-releasing hormone) systems in the goldfish brain using antibodies to salmon Gn-RH. Cell Tiss. Res. 244, $327-337$

Le Mevel J. C. and Mabin D. (1985) Evidence for biorhythmicity from the preoptic nucleus of the rainbow trout Salmo gairdneri under freely swimming conditions - An electrophysiological study. Comp. Biochem. Physiol. 82A, 29-33.

MacKenzie D. S., Gould D. R., Peter R. E., Rjvier J. and Vale W. E. (1984) Response of superfused goldfish pituitary fragments to mammalian and salmon gonadotropin-releasing hormone. Life Sci. 35, 2019-2026. 
Pasmanik M. and Callard G. V. (1988) Changes in brain aromatase and $5 \alpha$-reductase activitics correlate significantly with seasonal reproductive cycles in goldfish (Carassius auratus). Endocrinology 88, 1349-1356.

Peter R. E. (1983) Evolution of neurohormonal regulation of reproduction in lower vertebrates. Am. Zool. 23, 685-695.

Peter R. E. and Fryer J. N. (1983) Endocrine functions of the hypothalmus of Actinopterygians. In Fish Neurobiol ogy-Higher Brain Areas and Functions (Edited by Davis R. E. and Northcutt R. G.), Vol. 2, pp. 165-201. University of Michigan Press. Ann Arbor.

Peter R. E., Chang J. P., Nahorniak C. S., Omeljaniuk R. J., Sokolowska M., Shih S. H. and Billard R. (1986) Interactions of catecholamines and $\mathrm{GnRH}$ in regulation of gonadotropin secretion in teleost fish. Rec. Prog. Hor. Res. 42, 513-545.

Sherwood N. M. Zoeller R. T. and Moore F. L. (1986) Multiple forms of gonadotropin-releasing hormone in amphibians brain. Gen. comp. Endocr. 61, 313-322.

Schreibman M. P., Halpern-Sebold L., Ferin M., MargolisKazan and Goos H. J. Th. (1983) The effect of hypophysectomy and gonadotropin administration on the distribution and quantity of LH-RH in the brains of platyfish: a combined immunocytochemistry and radioimmunoassay study. Brain Res. 267, 293-300.

Van Der Kraak G., Lin H. R., Donaldson E. M., Dye H. M. and Hunter G. A. (1983) Effects of LH-RH and des-Gly ${ }^{10}\left[\mathrm{D}-\mathrm{Ala}^{6}\right] \mathrm{LH}-\mathrm{RH}$-ethylamide on plasma gonadotropin levels and oocyte maturation in adult female coho salmon (Oncorhynchus kisutch). Gen. comp. Endocr. 49, 470-476.

Weil C., Hansen P., Hyam D., Le Gac F., Breton B. and Crim L. W. (1986) Use of pituitary cells in primary culture to study the regulation of gonadotropin hormone $(\mathrm{GtH})$ secretion in rainbow trout: setting up and validating the system as assessed by its responsiveness to mammalian and salmon gonadotropin releasing hormone. Gen comp. Endocr. 62, 202-209.

Yu K. L., Sherwood N. M. and Peter R. E. (1988) Differential distribution of two molecular forms of gonadotropinreleasing hormone in discrete brain areas of goldfish (Carassius auratus). Peptides 9, 625-630.

Zohar Y., Breton B. and Fostier A. (1986) Short-time profile of plasma gonadotropin and estradiol-17 $\beta$ levels in female rainbow trout, from early ovarian recrudescence and throughout vitellogenesis. Gen. comp. Endocr. 64, $172-188$ 